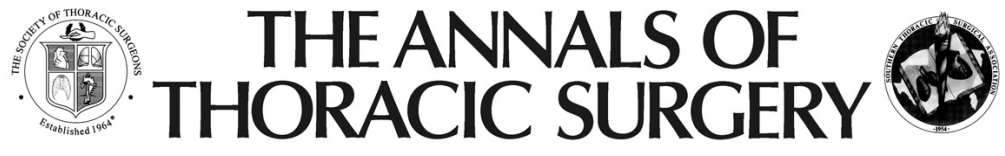

\section{Transhiatal Esophagectomy in the Profoundly Obese: Implications and Experience}

Christopher N. Scipione, Andrew C. Chang, Allan Pickens, Christine L. Lau and Mark B. Orringer

Ann Thorac Surg 2007;84:376-383

DOI: 10.1016/j.athoracsur.2006.11.070

The online version of this article, along with updated information and services, is located on the World Wide Web at:

http://ats.ctsnetjournals.org/cgi/content/full/84/2/376 


\title{
Transhiatal Esophagectomy in the Profoundly Obese: Implications and Experience
}

\author{
Christopher N. Scipione, MD, Andrew C. Chang, MD, Allan Pickens, MD, \\ Christine L. Lau, MD, and Mark B. Orringer, MD \\ Department of Surgery, Section of Thoracic Surgery, The University of Michigan Medical Center, Ann Arbor, Michigan
}

Background. Historically, obesity contraindicated an abdominal approach to the esophagogastric junction. The technique of transhiatal esophagectomy (THE) evolved without specific regard to body habitus. The dramatic increase in obese patients requiring an esophagectomy for complications of reflux disease prompted this evaluation of the impact of obesity on the outcomes of esophagectomy to determine whether profound obesity should contraindicate the transhiatal approach.

Methods. We used our Esophagectomy Database to identify 133 profoundly obese patients (body mass index $[\mathrm{BMI}] \geq 35 \mathrm{~kg} / \mathrm{m}^{2}$ ) from among 2176 undergoing a THE from 1977 to 2006 . This group was matched to a randomly selected, non-obese (BMI, 18.5 to $30 \mathrm{~kg} / \mathrm{m}^{2}$ ) control population of 133 patients. Intraoperative, postoperative, and long-term follow-up results were compared retrospectively.

$S^{i}$ ince the advent of the Belsey-Mark IV transthoracic hiatal hernia repair in 1952, many authors have argued that a transthoracic approach to the distal esophagus and esophagogastric junction for antireflux surgery is superior to a transabdominal one in obese patients given the increased difficulty encountered with esophageal mobilization, achieving a tension-free repair, and avoiding injury to the spleen in this patient population [1, 2]. Transhiatal esophagectomy (THE) was developed with the intent of reducing postoperative morbidity and mortality rates long associated with transthoracic esophagectomy.

Published reports of the results of THE have documented significantly less in-hospital mortality, operative blood loss, pulmonary complications, occurrence of chylothorax, shorter hospital and intensive care unit length of stay, and similar survival rates after both approaches for carcinoma $[3,4]$. The influence of body habitus on the results of esophagectomy was not considered in these reports nor, for that matter, in those which have debated

\footnotetext{
Accepted for publication Nov 21, 2006.

Presented at the Forty-third Annual Meeting of The Society of Thoracic Surgeons, San Diego, CA, Jan 29-31, 2007.

Address correspondence to Dr Orringer, Section of Thoracic Surgery, University of Michigan Medical Center, 1500 E Medical Center Dr, 2120 Taubman Center, Box 0344, Ann Arbor, MI 48109; e-mail: morrin@ umich.edu.
}

Results. Profoundly obese patients had significantly greater intraoperative blood loss (mean, $492.2 \mathrm{~mL}$ versus $361.8 \mathrm{~mL}, p=0.001)$, need for partial sternotomy (18 versus $3, p=0.001$ ), and frequency of recurrent laryngeal nerve injury ( 6 versus $0, p=0.04$ ). The two groups did not differ significantly in the occurrence of chylothorax, wound infection, or dehiscence rate; length of hospital stay or need for intensive care unit stay; or hospital or operative mortality. Follow-up results for dysphagia, dumping, regurgitation, and overall functional score were also comparable between the two groups.

Conclusions. With appropriate instrumentation, transhiatal esophagectomy in obese patients has similar morbidity and outcomes as in non-obese patients. Obesity, even when profound, does not contraindicate a transhiatal esophagectomy.

(Ann Thorac Surg 2007;84:376-83) (C) 2007 by The Society of Thoracic Surgeons

the relative merits or disadvantages of THE versus transthoracic esophagectomy over the years.

The effects of obesity on the surgical outcomes of THE is becoming an increasingly relevant issue given the growing rate of obesity in the United States. A 1998 National Institutes of Health (NIH) expert panel reported a 1988 to 1994 survey showing that $19.9 \%$ of men and $24.9 \%$ of women in the United States were obese, with a body mass index (BMI) of $30 \mathrm{~kg} / \mathrm{m}^{2}$ or more [5]. This represented a substantial increase in obesity compared with a previous 1976 to 1980 survey showing that $12.2 \%$ of men and $16.3 \%$ of women were obese.

The demographics of esophageal carcinoma in the United States have clearly changed during the past three decades. Esophageal cancer, which formerly had squamous cell histology and occurred in cachectic patients with a long history of alcohol and tobacco abuse, is now basically adenocarcinoma that occurs in obese patients with long-standing reflux. It is therefore appropriate to ask if the changing body habitus of patients with esophageal cancer should influence the surgical approach. This study was undertaken to determine if obesity poses unacceptably increased risk in patients undergoing THE, adding support to the historical argument that the transthoracic approach to the gastroesophageal junction and lower esophagus is preferable to a transabdominal procedure. 


\section{Patients and Methods}

\section{Patient Population}

This study was undertaken with prior approval of the University of Michigan Institutional Review Board. The University of Michigan Esophagectomy Database contains demographic, intraoperative, postoperative, and follow-up information for more than 2000 patients who have undergone a THE and cervical esophagogastric anastomosis at this center from 1977 to 2006.

Our technique of THE has been well described previously [6]. We have been performing this operation for 30 years, and in the past decade, a transition has taken place from routine closure of the abdominal incision with interrupted figure-of-eight \#1 monofilament sutures to running \#1 looped (double) monofilament suture on fascia, primarily to decrease operative time. Retention sutures and myofascial flaps are not used routinely. Wound packing is used only to treat wound infections. In patients unable to maintain adequate oral caloric intake preoperatively, nasoenteric tube feedings have been used rather than gastrostomy or jejunostomy feeding tubes.

Demographic information from this database was used to calculate the BMI from the preoperative visit weight in kilograms divided by preoperative visit height in meters squared $\left(\mathrm{kg} / \mathrm{m}^{2}\right)$. In $75 \%$ of this patient population, data on both height and weight were available for calculation of the BMI. A group of 133 patients with a BMI of $35 \mathrm{~kg} / \mathrm{m}^{2}$ or more was identified. This group was designated as profoundly obese, corresponding to the most recent NIH obesity classification of class $2\left(35.0\right.$ to $\left.39.9 \mathrm{~kg} / \mathrm{m}^{2}\right)$ or class 3 $\left(>40 \mathrm{~kg} / \mathrm{m}^{2}\right)$ [5]. Among these 133 profoundly obese patients, 102 had malignant disease and 31 had benign disease as the indication for esophagectomy. These obese patients were then matched to 133 non-obese controls with a BMI of 18.5 to $29.9 \mathrm{~kg} / \mathrm{m}^{2}$ (NIH classification of normal weight or overweight) [5].

The obese patients with cancer and those with benign disease were matched separately to control groups. The 102 obese cancer patients were matched for age, gender, year of surgery, race, tumor pathology, tumor site, adjuvant therapy (preoperative/postoperative chemotherapy or radiotherapy, or both), surgeon, postoperative pathologic tumor stage, surgical risk factors (diabetes, hypertension, cardiac disease, vascular disease, and stroke history), smoking history, and history of regular alcohol consumption. The benign disease patients were matched for age, gender, year of surgery, race, surgeon, surgical risk factors, smoking history, history of regular alcohol

Table 1. Demographics of Patients Undergoing Transhiatal Esophagectomy for Malignant Disease

\begin{tabular}{|c|c|c|c|}
\hline Characteristic & Obese $(n=102)$ & Non-obese $(\mathrm{n}=102)$ & $p$ Value \\
\hline Mean body mass index $\left(\mathrm{kg} / \mathrm{m}^{2}\right)$ & $40.1 \pm 4.8$ & $25.7 \pm 2.7$ & $<0.0001$ \\
\hline Gender (male/female) & $75 / 27$ & $77 / 25$ & 0.87 \\
\hline Mean Age (years) & $56.9 \pm 10.4$ & $60.4 \pm 11.8$ & 0.34 \\
\hline Year of Operation & $10 / 1981-2 / 2006$ & $7 / 1982-5 / 2006$ & 1.00 \\
\hline Race (white/other) & $97 / 5$ & $96 / 5$ & 0.48 \\
\hline Pathology (adenocarcinoma/squamous) & $96 / 6$ & $90 / 12$ & 0.22 \\
\hline Tumor Site $^{a}$ & $13 / 89$ & $11 / 91$ & 0.67 \\
\hline \multicolumn{4}{|l|}{ Adjuvant Therapy } \\
\hline Preoperative Radiation & 52 & 51 & 1.00 \\
\hline Preoperative Chemotherapy & 51 & 50 & 1.00 \\
\hline Postoperative Radiation & 11 & 11 & 0.82 \\
\hline Postoperative Chemotherapy & 9 & 12 & 0.64 \\
\hline Surgeon (senior surgeon/other) & $60 / 52$ & $66 / 46$ & 0.76 \\
\hline \multicolumn{4}{|l|}{ Pathologic tumor stage } \\
\hline Stage 0 & 9 & 9 & 1.00 \\
\hline Stage 1 & 34 & 34 & 1.00 \\
\hline Stage IIA & 18 & 18 & 1.00 \\
\hline Stage IIB & 14 & 14 & 1.00 \\
\hline Stage III & 27 & 27 & 1.00 \\
\hline \multicolumn{4}{|l|}{ Risk factors } \\
\hline Diabetes & 18 & 17 & 1.00 \\
\hline Hypertension & 32 & 26 & 0.44 \\
\hline Cardiac disease & 13 & 14 & 1.00 \\
\hline Vascular disease & 3 & 5 & 0.72 \\
\hline Stroke & 3 & 2 & 1.00 \\
\hline Smoking history & 64 & 65 & 0.92 \\
\hline Alcohol history & 35 & 40 & 0.52 \\
\hline
\end{tabular}

${ }^{a}$ Upper and Middle Esophagus/Lower Esophagus and Cardia. 
consumption, primary diagnosis, and history of esophageal operation(s).

Matching was done by sorting obese patients by the criteria and then coupling them with patients with similar clinical variables selected from a large non-obese THE population of 1048 cancer patients and 251 patients with benign disease to ensure a well-matched control group. From the standpoint of statistical validity, this method was determined to be at least as efficient as propensity matching because of the large pool of 1299 non-obese THE patients that facilitated the matching of variables.

After matching was completed, the Esophagectomy Database was used to provide a comparison of events:

- perioperative events-blood loss, need for partial sternotomy for exposure, splenectomy, tracheal laceration, pyloroduodenal mucosa entry during performance of a pyloromyotomy, need for chest tube placement, chylothorax, recurrent laryngeal nerve injury, and mortality;

- postoperative complications-pneumonia/atelectasis, cervical anastomotic leak, atrial fibrillation, gastric tip necrosis, cervical wound infection, abdominal wound infection, abdominal wound dehiscence, pneumothorax, mediastinal bleeding, need for intensive care unit stay, hospital mortality, need for reoperation, and other complications;

- hospital length of stay; and

- long-term follow-up data-incidence and severity of dysphagia, regurgitation, and dumping, as well as overall functional score.

The medical records (operative reports and discharge summaries) for all 266 patients included in the study were reviewed to verify completeness and accuracy of the database.

\section{Definition of Clinical Variables}

Patients were considered to have cardiac disease if they had clinically significant coronary artery disease, a history of myocardial infarction or coronary intervention, or documented heart failure. Smoking history was denoted as positive if the patient had ever smoked any amount of cigarettes on a daily basis. A history of alcohol use was considered positive if the patient reported regular alcohol consumption on a daily basis at any time.

In assessing postoperative functional results, "mild" dysphagia was defined as occasional symptoms requiring no treatment, "moderate" dysphagia necessitated occasional esophageal dilatations, and "severe" dysphagia required regular esophageal dilatations. Dumping was defined as "mild" if postprandial cramping or diarrhea required no treatment, "moderate" if it required occasional medication, and "severe" if it required regular medical therapy. Regurgitation was defined as "mild" if it was occasional after a large meal or while recumbent, "moderate" if it required the patient to sleep upright at night to avoid regurgitation, and "severe" if pulmonary complications from aspiration were documented. Overall functional result was considered to be "excellent" if the patient was asymptomatic and required no treatment, "good" if mildly symptomatic requiring no treatment, "fair" if mildly symptomatic requiring occasional treatment such as dilation or antidiarrheal medication, or "poor" if symptoms required regular treatments.

Table 2. Demographics of Patients Undergoing Transhiatal Esophagectomy for Benign Disease

\begin{tabular}{|c|c|c|c|}
\hline Characteristic & Obese $(n=31)$ & Non-Obese $(\mathrm{n}=31)$ & $p$ Value \\
\hline Mean body mass index $\left(\mathrm{kg} / \mathrm{m}^{2}\right)$ & $39.2 \pm 5.0$ & $25.8 \pm 3.1$ & $<0.0001$ \\
\hline Gender (male/female) & $18 / 13$ & $18 / 13$ & 0.80 \\
\hline Mean age (years) & $58.5 \pm 10.4$ & $59.0 \pm 12.1$ & 0.86 \\
\hline Year of operation & $6 / 1981-3 / 2006$ & $11 / 1985-7 / 2005$ & 1.00 \\
\hline Race (white/other) & $29 / 2$ & $29 / 2$ & 0.61 \\
\hline Surgeon (senior surgeon/other) & $20 / 11$ & $22 / 9$ & 0.86 \\
\hline \multicolumn{4}{|l|}{ Primary diagnosis } \\
\hline Barrett high grade dysplasia & 24 & 24 & 1.00 \\
\hline Achalasia & 4 & 4 & 1.00 \\
\hline Caustic injury & 1 & 1 & 1.00 \\
\hline Recurrent Gastroesophageal Reflux & 1 & 1 & 1.00 \\
\hline Dysmotility & 1 & 1 & 1.00 \\
\hline \multicolumn{4}{|l|}{ Risk Factors } \\
\hline Diabetes & 4 & 4 & 0.70 \\
\hline Hypertension & 16 & 16 & 0.80 \\
\hline Cardiac disease & 6 & 6 & 0.75 \\
\hline Vascular disease & 2 & 2 & 0.61 \\
\hline Stroke & 2 & 2 & 0.61 \\
\hline Smoking history & 21 & 22 & 1.00 \\
\hline Alcohol history & 6 & 6 & 0.75 \\
\hline Prior esophageal operations (No/Yes) & $24 / 7$ & $22 / 9$ & 0.57 \\
\hline
\end{tabular}


Table 3. Intraoperative and Postoperative Events in Patients Undergoing Transhiatal Esophagectomy

\begin{tabular}{|c|c|c|c|c|c|c|c|c|c|}
\hline \multirow[b]{2}{*}{ Event } & \multicolumn{2}{|c|}{ Malignant Disease } & \multirow[b]{2}{*}{$p$ Value } & \multicolumn{2}{|c|}{ Benign Disease } & \multirow[b]{2}{*}{$p$ Value } & \multicolumn{2}{|c|}{ Total Series } & \multirow[b]{2}{*}{$p$ Value } \\
\hline & $\begin{array}{c}\text { Obese } \\
(\mathrm{n}=102) \\
(\%)\end{array}$ & $\begin{array}{c}\text { Non-Obese } \\
(\mathrm{n}=102) \\
(\%)\end{array}$ & & $\begin{array}{c}\text { Obese } \\
(\mathrm{n}=31) \\
(\%)\end{array}$ & $\begin{array}{c}\text { Non-Obese } \\
(\mathrm{n}=31) \\
(\%)\end{array}$ & & $\begin{array}{c}\text { Obese } \\
(\mathrm{n}=133) \\
(\%)\end{array}$ & $\begin{array}{c}\text { Non-Obese } \\
(\mathrm{n}=133) \\
(\%)\end{array}$ & \\
\hline \multicolumn{10}{|l|}{ Intraoperative } \\
\hline Mean blood loss (mL) & 513 & 367 & 0.001 & 422 & 346 & 0.29 & 492 & 362 & 0.001 \\
\hline Partial stemotomy & $13(13)$ & $2(2)$ & 0.007 & $5(16)$ & $1(3)$ & 0.20 & $18(14)$ & $3(2)$ & 0.001 \\
\hline Splenectomy & $1(1)$ & $3(3)$ & 0.61 & 0 & 0 & - & $1(1)$ & $3(2)$ & 0.61 \\
\hline Tracheal laceration & 0 & 0 & - & 0 & $1(3)$ & 1.00 & 0 & $1(1)$ & 1.00 \\
\hline $\begin{array}{l}\text { Pyloroduodenal mucosal } \\
\text { Entry }\end{array}$ & $10(10)$ & $7(7)$ & 0.61 & $2(7)$ & $4(13)$ & 0.67 & $12(9)$ & $11(8)$ & 1.00 \\
\hline Need for chest tube & $53(52)$ & $65(64)$ & 0.23 & $16(52)$ & $15(48)$ & 0.43 & $69(52)$ & $80(55)$ & 0.31 \\
\hline Chylothorax & $4(4)$ & $1(1)$ & 0.37 & 0 & 0 & - & $4(3)$ & $1(1)$ & 0.37 \\
\hline RLN injury & $4(4)$ & 0 & 0.13 & $2(7)$ & 0 & 0.47 & $6(4.5)$ & 0 & 0.04 \\
\hline Mortality & $1(1)$ & 0 & 1.00 & 0 & 0 & - & $1(1)$ & 0 & 1.00 \\
\hline \multicolumn{10}{|l|}{ Postoperative } \\
\hline Pneumonia/atelectasis & $7(7)$ & $11(11)$ & 0.46 & $5(16)$ & $3(10)$ & 0.70 & $12(9)$ & $14(11)$ & 0.84 \\
\hline $\begin{array}{l}\text { Cervical anastomotic } \\
\text { leak }\end{array}$ & $19(19)$ & $13(13)$ & 0.34 & $3(10)$ & $6(19)$ & 0.47 & $22(17)$ & $19(14)$ & 0.73 \\
\hline Atrial fibrillation & $17(17)$ & $10(10)$ & 0.22 & $2(7)$ & $2(7)$ & 0.61 & $19(14)$ & $12(9)$ & 0.25 \\
\hline Gastric tip necrosis & $2(2)$ & $1(1)$ & 1.00 & 0 & $1(3)$ & 1.00 & $2(2)$ & $2(2)$ & 0.61 \\
\hline \multicolumn{10}{|l|}{ Wound infection } \\
\hline Cervical/Sternal & $4(4)$ & $4(4)$ & 0.72 & 0 & 0 & - & $4(3)$ & $4(3)$ & 0.72 \\
\hline Abdominal & $3(3)$ & $11(11)$ & 0.053 & $1(3)$ & 0 & 1.00 & $4(3)$ & $11(8.3)$ & 0.11 \\
\hline $\begin{array}{l}\text { Abdominal wound } \\
\text { dehiscence }\end{array}$ & $7(7)$ & $3(3)$ & 0.33 & $2(7)$ & 0 & 0.47 & $9(7)$ & $3(3)$ & 0.14 \\
\hline Pneumothorax & $2(2)$ & $5(5)$ & 0.44 & $1(3)$ & $3(10)$ & 0.61 & $3(3)$ & $8(6)$ & 0.22 \\
\hline Mediastinal bleed & 0 & $1(1)$ & 1.00 & 0 & 0 & - & 0 & $1(1)$ & 1.00 \\
\hline Need for ICU stay & $34(33)$ & $33(32)$ & 1.00 & $10(32)$ & $9(29)$ & 1.00 & $44(33)$ & $42(32)$ & 0.90 \\
\hline Hospital mortality & $4(4)$ & $2(2)$ & 0.66 & 0 & 0 & - & $4(3)$ & $2(2)$ & 0.71 \\
\hline Reoperation & $8(8)$ & $10(10)$ & 0.81 & $2(7)$ & $3(10)$ & 1.00 & $10(8)$ & $13(10)$ & 0.66 \\
\hline Other complications & $15(15)$ & $11(11)$ & 0.53 & $6(19)$ & $2(7)$ & 0.26 & $21(16)$ & $13(10)$ & 0.20 \\
\hline $\begin{array}{l}\text { Days of hospital stay } \\
\text { (mean) }\end{array}$ & $11.4 \pm 8.6$ & $12.8 \pm 14.3$ & 0.40 & $12.7 \pm 16.5$ & $10.0 \pm 8.0$ & 0.42 & $11.7 \pm 10.9$ & $12.1 \pm 13.2$ & 0.79 \\
\hline
\end{tabular}

ICU = intensive care unit; $\quad$ RLN = recurrent laryngeal nerve.

\section{Statistical Analysis}

Data analysis was performed with a personal computer using STAT-SAK 2.40 for MS-DOS (Gerrard Dallal, Malden, MA). Categoric data with one degree of freedom were analyzed with $\chi^{2}$ testing with Yates correction. Categoric data with more than one degree of freedom were analyzed with standard $\chi^{2}$ testing. Continuous variables were analyzed with a two-sample $t$ test. Statistical significance was defined as $p<0.05$.

\section{Results}

\section{Patient Characteristics}

The demographics and preoperative medical risk factors were similar between the profoundly obese and nonobese groups with cancer (Table 1) and benign disease (Table 2). The obese cancer patients had a slightly higher but statistically insignificant rate of adenocarcinoma than their non-obese counterparts (96/102 versus 90/102, $p=$ $0.22)$.

\section{Intraoperative and Postoperative Outcomes}

Intraoperative mean blood loss $(492 \mathrm{~mL}$ versus $362 \mathrm{~mL}$, $p=0.001)$, need for a partial sternotomy (18 versus $3, p=$ 0.001 ), and recurrent laryngeal nerve injury ( 6 versus 0 , $p=0.04$ ) were all significantly greater in the profoundly obese patients when those with cancer and benign disease groups were considered as one group (Table 3 ). The incidence of splenectomy, intraoperative tracheal laceration, pyloroduodenal mucosal injury during pyloromyotomy, pleural space entry necessitating chest tube placement, chylothorax, and intraoperative mortality were similar in obese and nonobese patients.

Postoperative events such as pneumonia/atelectasis, cervical anastomotic leak, atrial fibrillation, gastric tip necrosis, cervical wound infection, abdominal wound infection and dehiscence, pneumothorax, mediastinal bleeding, need for intensive care unit stay, duration of hospital stay, hospital mortality rate, need for reoperation, and other documented complications did not differ significantly in obese versus non-obese patients. Obese 
patients tended to have higher rates of abdominal wound dehiscence ( 9 versus $3, p=0.14$ ). Abdominal wound infection rates tended to occur more often in the nonobese patients ( 11 versus $4, p=0.11$ ). When abdominal wound infection rates in the cancer population only were considered, the difference neared statistical significance for increased wound infection rate in the non-obese individuals (11 versus $3, p=0.053$ ).

Ten of the obese patients required reoperation for major anastomotic leak in 3 patients, and 1 patient each with wound dehiscence, herniation of the splenic flexure through the diaphragmatic hiatus, drainage of an epidural abscess and partial diskectomy, chyle leak, sternal infection, vertebral disk herniation repair, or need for tracheostomy. In the non-obese group, 13 patients reoperation for anastomotic leak or disruption in 2, and 1 patient each with sternal wound infection, chyle leak, esophagopleural fistula, need for hemicolectomy for bowel injury, need for radical debridement of a necrotizing abdominal wound infection, thrombosis of an aortofemoral bypass graft, wound dehiscence, pacemaker implantation and mediastinal hematoma removal, reexploration for pneumomediastinum on imaging, lysis of adhesions for partial small-bowel obstruction, or cervical esophagostomy for necrosis of gastric tip.

The obese patients sustained 21 other complications, including 3 patients each with acute renal failure, urinary tract infection, or empyema; 2 patients each with Clostridium difficile infection or thrombophlebitis; and 1 patient each with pressure sore, deep venous thrombosis, radial nerve injury, intraabdominal abscess, mediastinal abscess, vertebral disk herniation, cardiac arrhythmia, or paraplegia secondary to an epidural abscess. Fifteen other complications occurred in the non-obese group, including urinary tract infection in 4, empyema formation in 3 , and 1 patient each with $C$. difficile colitis, acute renal failure, pulmonary embolus, aortofemoral graft thrombosis, cecal perforation, or esophagopleural fistula formation.

All hospital and operative deaths occurred in patients with cancer as the indication for THE. The four deaths in the obese group were caused by sudden cardiopulmonary arrest, probable stroke, intestinal ischemia, or an unknown cause while sleeping. Two non-obese patients

Table 4. Functional Results of Esophageal Substitution with Stomach After Transhiatal Esophagectomy

\begin{tabular}{|c|c|c|c|c|c|c|c|c|c|}
\hline \multirow[b]{2}{*}{ Result } & \multicolumn{2}{|c|}{ Malignant Disease } & \multirow[b]{2}{*}{$p$ Value } & \multicolumn{2}{|c|}{ Benign Disease } & \multirow[b]{2}{*}{$p$ Value } & \multicolumn{2}{|c|}{ Total Series } & \multirow[b]{2}{*}{$p$ Value } \\
\hline & $\begin{array}{l}\text { Obese } \\
\text { n }(\%)\end{array}$ & $\begin{array}{c}\text { Non-Obese } \\
n(\%)\end{array}$ & & $\begin{array}{l}\text { Obese } \\
\text { n }(\%)\end{array}$ & $\begin{array}{c}\text { Non-Obese } \\
n(\%)\end{array}$ & & $\begin{array}{l}\text { Obese } \\
\text { n }(\%)\end{array}$ & $\begin{array}{c}\text { Non-Obese } \\
\mathrm{n}(\%)\end{array}$ & \\
\hline Mean follow-up (months) & 29 & 33 & 0.58 & 37 & 37 & 0.98 & 31 & 34 & 0.63 \\
\hline \multicolumn{10}{|l|}{ Dysphagia $^{\mathrm{a}}$} \\
\hline Total & 77 & 67 & 0.04 & 25 & 29 & 0.69 & 102 & 96 & 0.14 \\
\hline None & $62(81)$ & $49(73)$ & & $15(60)$ & $16(55)$ & & $77(75)$ & $65(68)$ & \\
\hline Mild & $3(4)$ & $11(16)$ & & $4(16)$ & $3(10)$ & & $7(7)$ & $14(15)$ & \\
\hline Moderate & $12(16)$ & $6(9)$ & & $6(24)$ & $9(31)$ & & $18(18)$ & $15(16)$ & \\
\hline Severe & 0 & $1(2)$ & & 0 & $1(3)$ & & 0 & $2(2)$ & \\
\hline \multicolumn{10}{|l|}{ Regurgitation $^{\mathrm{b}}$} \\
\hline Total & 76 & 67 & 0.44 & 25 & 29 & 0.74 & 101 & 96 & 0.30 \\
\hline None & $49(65)$ & $47(70)$ & & $13(52)$ & $13(45)$ & & $62(61)$ & $60(63)$ & \\
\hline Mild & $25(33)$ & $16(24)$ & & $9(36)$ & $10(35)$ & & $34(34)$ & $26(27)$ & \\
\hline Moderate & $2(3)$ & $3(5)$ & & $3(12)$ & $5(17)$ & & $5(5)$ & $8(8)$ & \\
\hline Severe & 0 & $1(2)$ & & 0 & $1(3)$ & & 0 & $2(2)$ & \\
\hline \multicolumn{10}{|l|}{ Dumping $^{\mathrm{c}}$} \\
\hline Total & 72 & 60 & 0.94 & 23 & 24 & 0.62 & 95 & 84 & 0.89 \\
\hline None & $51(71)$ & $40(67)$ & & $12(52)$ & $12(50)$ & & $63(66)$ & $52(62)$ & \\
\hline Mild & $15(21)$ & $14(23)$ & & $8(35)$ & $6(25)$ & & $23(24)$ & $20(24)$ & \\
\hline Moderate & $5(7)$ & $3(5)$ & & $3(13)$ & $5(21)$ & & $8(8)$ & $8(10)$ & \\
\hline Severe & $1(1)$ & $1(2)$ & & 0 & $1(4)$ & & $1(1)$ & $2(2)$ & \\
\hline \multicolumn{10}{|l|}{ Overall functional result ${ }^{\mathrm{d}}$} \\
\hline Total & 70 & 64 & 0.72 & 23 & 27 & 0.77 & 93 & 91 & 0.25 \\
\hline Excellent & $31(44)$ & $26(41)$ & & $4(17)$ & $5(19)$ & & $35(38)$ & $31(34)$ & \\
\hline Good & $22(31)$ & $21(33)$ & & $10(44)$ & $7(26)$ & & $32(34)$ & $28(31)$ & \\
\hline Fair & $16(23)$ & $14(22)$ & & $9(39)$ & $12(44)$ & & $25(27)$ & $26(29)$ & \\
\hline Poor & $1(1)$ & $3(5)$ & & 0 & 3 (11) & & $1(1)$ & $6(7)$ & \\
\hline
\end{tabular}

${ }^{\text {a }}$ Mild = occasional symptoms needing no treatment, moderate $=$ requiring occasional esophageal dilatations, severe $=$ requiring regular dilatations). $\quad{ }^{\mathrm{b}}$ Mild = occasional symptoms, moderate = patient required to sleep upright to avoid regurgitation, severe $=$ pulmonary complications from aspiration documented). $\quad{ }^{\mathrm{c}}$ Mild $=$ occasional cramping or diarrhea requiring no treatment, moderate $=$ symptoms require occasional medication, severe $=$ symptoms require regular medical therapy. $\quad{ }^{\mathrm{d}}$ Excellent $=$ asymptomatic, good $=$ symptomatic requiring no treatment, fair $=$ symptomatic requiring occasional treatment, poor $=$ symptomatic requiring regular treatment. 
died during their hospital stay, both from cardiopulmonary arrest. The lone operative death in this series occurred in a profoundly obese cancer patient and was due to a left atrial tear during esophageal mobilization.

\section{Postoperative Outcomes}

The functional outcomes of esophageal substitution with stomach were similar between the profoundly obese and non-obese patients (Table 4). Overall, more non-obese individuals tended to have some symptoms of dysphagia ( $32 \%$ versus $24 \%, p=0.14)$, and the difference was driven by higher rates of mild dysphagia requiring no clinical intervention. When analyzing the data from cancer patients only (Table 4), the occurrence of dysphagia became significantly higher in non-obese individuals ( $27 \%$ versus $20 \%, p=0.04$ ), but once again this difference is driven by higher rates of mild dysphagia in the non-obese individuals.

\section{Comment}

The current epidemic of obesity in this country has direct implication for the dramatic increased prevalence of hiatal hernia, gastroesophageal reflux disease, Barrett metaplasia, and esophageal adenocarcinoma. Paralleling the rise in obesity, the incidence of esophageal adenocarcinoma increased by $350 \%$ between 1976 and 1994 [7]. A review by Nilsson and Lagergren [8] demonstrated the correlation between body mass and esophageal reflux symptoms. The odds ratio (OR) of reflux symptoms in subjects with a BMI exceeding $35 \mathrm{~kg} / \mathrm{m}^{2}$ compared with those with a BMI of less than $25 \mathrm{~kg} / \mathrm{m}^{2}$ was 3.3 for men (95\% confidence interval [CI], 2.4 to 4.7 ) and 6.3 for women ( $95 \% \mathrm{CI}, 4.9$ to 8.0 ). Manometric findings in a study by Wajed and colleagues [9] revealed significantly greater distal esophageal acid exposure in overweight and obese individuals (BMI $>25 \mathrm{~kg} / \mathrm{m}^{2}$ ) compared with non-obese individuals (BMI, 18.5 to $25 \mathrm{~kg} / \mathrm{m}^{2} ; p<0.01$ ).

A 2006 study of more than 10,000 women reported by Jacobson and colleagues [10] showed a direct relationship between increasing BMI and frequent symptoms of esophageal reflux. Furthermore, this study showed a significant increase in frequent reflux symptoms amongst women with a normal baseline BMI who had an increase in their BMI of 3.5 or more $(p=0.002)$. Lagergren and colleagues [11] showed that increasing BMI is associated with an increase in esophageal adenocarcinoma (OR, 16.2; $95 \%$ CI, 6.3 to 41.4 ) for individuals with a BMI $>30$ $\mathrm{kg} / \mathrm{m}^{2}$ compared with individuals with a BMI $<22 \mathrm{~kg} / \mathrm{m}^{2}$.

At a molecular level, Moe and colleagues [12] determined that an elevated waist-to-hip ratio and weight gain since the age of 25 were associated with a higher percentage of cells in the $S$ and G2 phase in biopsy samples of patients with Barrett esophagus, predisposing them to progression from Barrett esophagus to esophageal adenocarcinoma. Finally, one review of nutritional influences on the risk of developing esophageal cancer concluded that dietary fat intake was associated with the development of adenocarcinoma of the esophagus [13].
This study documents surprisingly similar surgical outcomes with THE in profoundly obese and non-obese patients. Two previous analyses by Orringer and colleagues [14, 15] reported similarly low morbidity and mortality as in this current study (3\% need for splenectomy, $<1 \%$ tracheal laceration, $<1 \%$ chylothorax, $<1 \%$ mediastinal hemorrhage, $<1 \%$ operative mortality, and $4 \%$ hospital mortality). The current series also reinforces the documented trend in decreased mortality after esophagectomy seen nationally in high-volume centers $(11.0 \%$ to $7.5 \%, p=0.003)$, but not in low-volume centers $(15.3 \%$ to $14.5 \%, p=0.8)$, as technical refinements have been made in THE [16]. Technical aids such as the Buchwalter table-mounted retractor with deep liverretracting blades, special-order long, right-angle clamps (15 to 17 inches), and long electrocautery extensions have been used at our institution to aid in exposure of the gastroesophageal junction and transhiatal esophageal mobilization in obese patients.

The mean blood loss was statistically significantly greater in obese patients ( $492 \mathrm{~mL}$ versus $362 \mathrm{~mL}, p=0.001$ ), but this difference has little clinical significance. In one report by Orringer and colleagues [15], mean intraoperative blood loss in 50 consecutive THE patients was $1166 \mathrm{~mL}$ from 1978 to $1980,505 \mathrm{~mL}$ in 50 consecutive patients from 1991 to 1992, and $316 \mathrm{~mL}$ for 114 consecutive procedures from 1996 to 1997. A 2006 study on THE and arrhythmias incidentally reported an average blood loss of $620 \mathrm{~mL}$ [17]. The mean blood loss in this current study represents the continuing trend of improved hemostasis during the transhiatal mediastinal dissection owing to more direct clamping and ligating and cauterization of periesophageal tissue and less blunt dissection.

Another significant difference between the two groups was the need for a partial sternotomy to gain access to the cervical esophagus (18 in obese versus 3 in non-obese patients, $p=0.001$ ). This technique is needed in THE patients with a "bull-neck" habitus and relatively little length of cervical esophagus [18]. Of the 21 patients in this series undergoing a partial sternotomy, 1 obese and 1 non-obese patient required reoperation to drain a sternal wound infection. This adverse outcome is uncommon, and although unpleasant, generally responds well to drainage and packing.

The overall rate of recurrent laryngeal nerve (RLN) injury in the current study was less than $3 \%$. This is consistent with previous data reported by Orringer and colleagues [14] showing a decline in RLN injury from $32 \%$ (1978 to 1982 ) to $5 \%$ (1983 to 1987 ) to $2 \%$ (1993 to 1997) [14]. This decline is attributed to greater experience with cervical esophageal mobilization and strict avoidance of the placement of metal retractors against the tracheoesophageal groove. However, all of the RLN injuries in the current study occurred in the profoundly obese group (6 versus $0, p=0.04$ ), a further acknowledgement of the increased difficulty mobilizing the cervical esophagus in a very obese patient with a short, wide, and deep neck.

A study by Gockel and colleagues [19] on RLN injury after esophagectomy reported an increased incidence of 
postoperative pneumonia in patients with RLN injury (33/63 with RLN injury compared with 90/341 without RLN injury, $p=0.027$ ). This same study also showed no significant difference in either the 30-day mortality rate or longterm survival after RLN injury despite the significant increase in postoperative pneumonia. The increase in postoperative pneumonia reported by Gockel and colleagues was not seen in our profoundly obese patients despite the significant increase in RLN injury in this group.

One unexpected result of the study was the trend for an increased rate of abdominal wound infection in nonobese patients undergoing a THE $(8 \%$ in the total study population versus $3 \%, p=0.11 ; 10.8 \%$ in cancer patients only versus $2.9 \%, p=0.053$ ). This finding is inconsistent with the results of a study by Smith and colleagues [20] in which increasing BMI in individuals undergoing elective colorectal resection was associated with an increased risk of surgical site infection. This latter study, however, did not control for differences in confounding variables such as cardiac disease, poor glucose control, and smoking history that may contribute to higher rates of surgical site infection in obese individuals.

Another study of wound infection rates by Arabshahi and Koohpayezade [21] points out that diabetes mellitus (OR, 4.9; 95\% CI, 4.0 to 6.1), smoking history (OR, 3.1; 95\% CI, 2.5 to 3.7), and obesity (OR, 4.1; $95 \%$ CI, 3.2 to 5.1 ) all increase the likelihood of surgical site infection. Furthermore, Pan and colleagues [22] found that in patients undergoing primary coronary artery bypass grafting, increasing BMI is associated with a higher rate of leg wound infection in individuals with diabetes mellitus but not in individuals without diabetes.

Taken together, the results of these latter studies suggest that increasing BMI alone may not dramatically increase the rate of wound infection; rather, comorbidities associated with a higher BMI, such as diabetes, may play a major role in raising wound infection rates. Perhaps the nonobese patients requiring esophagectomy had a higher rate of abdominal wound complications owing to relatively poorer nutrition and more severely altered immunologic status than their obese counterparts.

In conclusion, the outcomes of transhiatal esophagectomy and cervical esophagogastric anastomosis in profoundly obese patients in a high volume center are generally comparable with those in non-obese patients. These findings combined with the demonstrated lower morbidity of the transhiatal versus transthoracic approach in the general population of patients undergoing esophagectomy suggest that THE is also a valid approach in obese patients who require an esophagectomy.

We thank Ken Guire, MS, a biostatistician and research assistant in the Department of Biostatistics within the School of Public Health at the University of Michigan.

\section{References}

1. Stylopoulos N, Rattner DW. The history of hiatal hernia repair. Ann Surg 2005;241:185-93.
2. Alexiou C, Beggs D, Salama F, Beggs L, Knowles KR. A tailored surgical approach for gastro-oesophageal reflux disease: the Nottingham experience. Eur J Cardiothorac Surg 2000;17:389-95.

3. Hulscher JB, Tijssen JG, Obertop H. Transthoracic versus transhiatal resection for carcinoma of the esophagus: a meta-analysis. Ann Thorac Surg 2001;72:306-13.

4. Hulscher JB, Sandick JW, DeBoer A. Extended transthoracic resection compared with limited transhiatal resection for adenocarcinoma of the esophagus. N Engl J Med 2002;347: 1662-9.

5. National Institute of Health, National Heart, Lung, and Blood Institute (NHLBI) Expert Panel Publication. The clinical guidelines on the identification, evaluation, and treatment of overweight and obesity in adults: evidence report. June 1998. Available at www.nhlbi.nih.gov. Accessed Aug 30, 2006.

6. Orringer MB. THE without thoracotomy. In: Cohn, LH, Patterson, A, eds. Operative techniques in thoracic and cardiovascular surgery. Spring ed. Philadelphia, PA: Elselvier, Inc; 2005:63-83.

7. Devesa SS, Blot WJ, Fraumeni JF. Changing patterns in the incidence of esophageal and gastric carcinoma in the United States. Cancer 1998;83:2049-53.

8. Nilsson M, Lagergren J. The relation between body mass and gastro-oesophageal reflux. Best Pract Res Clin Gastroenterol 2004;18:1117-23.

9. Wajed SA, Streets CG, Bremner CG, DeMeester TR. Elevated body mass disrupts the barrier to gastroesophageal reflux. Arch Surg 2001;136:1014-9.

10. Jacobson BC, Somers SC, Fuchs CS, Kelly CP, Camargo CA Jr. Body-mass index and symptoms of gastroesophageal reflux in women. N Engl J Med 2006;354:2340-8.

11. Lagergren J, Bergstrom R, Nyren O. Association between body mass and adenocarcinoma of the esophagus and gastric cardia. Ann Intern Med 1999;130:883-90.

12. Moe GL, Kristal AR, Levine DS, Vaughan TL, Reid BJ. Waist-to-hip ratio, weight gain, and dietary serum selenium are associated with DNA content flow cytometry in Barrett's esophagus. Nutr Cancer 2000;36:7-13.

13. Mayne ST, Navarro SA. Diet, obesity, and reflux in the etiology of adenocarcinomas of the esophagus and gastric cardia in humans. J Nutr 2002;132:3467S-70S.

14. Orringer MB, Marshall B, Iannettoni MD. Transhiatal esophagectomy: clinical experience and refinements. Ann Surg 1999;230:392-403.

15. Orringer MB, Marshall B, Iannettoni MD. Transhiatal esophagectomy for treatment of benign and malignant disease. World J Surg 2001;25:196-203.

16. Dimick JB, Wainess RM, Upchurch GR Jr, Iannettoni MD, Orringer MB. National trends in outcomes for esophageal resection. Ann Thorac Surg 2005;79:212-8.

17. Malhotra SK, Kaur RP, Gupta NM, Grover A, Ramprabu K, Nakra D. Incidence and types of arrhythmias after mediastinal manipulation during transhiatal esophagectomy. Ann Thorac Surg 2006;82:298-302.

18. Orringer MB. Partial median sternotomy: anterior approach to the upper thoracic esophagus. J Thorac Cardiovasc Surg 1984;87:124-9.

19. Gockel I, Kneist W, Keilman A, Juninger T. Recurrent laryngeal nerve paralysis (RLNP) following esophagectomy for carcinoma. Eur J Surg Oncol 2005;31:277-81.

20. Smith RL, Bohl JK, McElearney ST, et al. Wound infection after elective colorectal resection. Ann Surg 2004;239:599-607.

21. Arabshahi KS, Koohpayezade J. Investigation of risk factors for surgical wound infection among teaching hospitals in Tehran. Int Wound J 2006;3:59-62.

22. Pan W, Hindler $K$, Lee VV, Vaughn WK, Collard CD. Obesity in diabetic patients undergoing coronary artery bypass graft surgery is associated with increased postoperative morbidity. Anesthesiology 2006;104:441-7. 
DR WAYNE HOFSTETTER (Houston, TX): I want to congratulate you on your excellent results and also an excellent presentation.

I have two questions. One, we know that massive obesity comes with other comorbidities, and the one that we're seeing very frequently and I'm interested in is how you're managing is those patients with sleep apnea. A significant amount of patients are coming in who are requiring nightly continuous positive airway pressure (CPAP) and they have undergone esophagectomy with a cervical anastomosis. How are you dealing with their CPAP at night? Are you allowing it on a fresh anastomosis? The second question, have you considered moving over to the minimally invasive procedure for these obese patients?

DR ORRINGER: Yes, some of our very obese patients have had sleep apnea, and we have allowed CPAP to continue postoperatively. Interestingly, a number of our obese esophageal carcinoma patients, when they have gone through phase 1 of our "preoperative weight-reduction program," which is preoperative chemotherapy and radiation, have had improvement in their sleep apnea symptoms as they have lost weight. But yes, we have used CPAP postoperatively, and so long as there is a nasogastric tube in place, you have a "vent" to prevent them from building up pressure within the intrathoracic stomach and stressing the anastomosis against a closed upper esophageal sphincter.

Regarding your second question, no, I would hate to think about doing a minimally invasive gastric mobilization and transposition in somebody who weighs 240 or more pounds. I can't really speak to the minimally invasive approach in these patients, as I do not use it, but I have my concerns about it. One has to be sure that the hiatus is properly enlarged before passing the mobilized stomach into the posterior mediastinum. In an obese patient, when you mobilize the stomach and preserve the right gastroepiploic arcade, as many of you know, you wind up with a large wad of fat along the greater curvature of the stomach, and the hiatus must be intentionally enlarged in these patients to accommodate that. Because if you try to just push or drag all that up through the hiatus, you may wind up with vascular compromise of the stomach from compression at the level of the hiatus. So I believe that it is very important to be able to get your forearm up through the hiatus after the esophagectomy and to make sure that that hiatus is wide enough to accommodate the stomach with that extra wad of fat along the greater curvature. I really would not want to do this operation without that tactile sensation. Regarding the problem of abdominal wound dehiscence, we have found in the past six to eight cases that routine use of a large abdominal binder postoperatively in our very obese transhiatal esophagectomy patients has seemed to have made a noticeable difference, and we now place a binder in the operating room at the conclusion of the case to provide extra support during coughing and ambulation of these patients. I am not yet ready to advise sacrificing exposure for the sake of a smaller skin incision in obese patients requiring a transhiatal esophagectomy.
DR MICHAEL EPPINGER (San Antonio, TX): First of all, I want to congratulate Mr Scipione on an excellent presentation and on surviving Dr Orringer's red-ink process to get here.

As in a lot of other operations, you know, you looked back since 1977 , but my suspicion is that 130 of the 133 are relatively recent. The intensive care unit (ICU) length of stay is no different, but the vast majority of these patients who get operated on for esophagectomies don't go to the ICU. If you look at them, at the more recent cohort, is there any difference in their ICU length of stay?

DR ORRINGER: Mike, this cohort of profoundly obese transhiatal esophagectomy patients spans our nearly 30-year experience with this operation. But as you have correctly indicated, we have had more obese patients who have developed Barrett's adenocarcinomas in the last 10 to 15 years. But we just do not put the majority of these patients in the ICU postoperatively. They are "hammered" pretty hard preoperatively and told that the cards are stacked against them for many reasons, and they are really going to have to "put out" and continue postoperatively the preoperative walking and the deep breathing that we initiate. And it is amazing to me how many of them turn out to be among our best patients. They are highly motivated to get up and get going right away despite their size. Their postoperative length of stay has not differed significantly from that of our nonobese patients.

DR RICHARD I. WHYTE (Stanford, CA): I think one of the statistically significant differences you found had to do with both infection rate and dehiscence, and dehiscences were higher in the obese patients and infections were higher in the nonobese patients, and I find that a bit surprising.

DR ORRINGER: You have focused on an interesting finding of this work. Intuitively, we expected the rates of both wound dehiscence and infection to be higher in the profoundly obese patients. Interestingly, while there were more dehiscences in the obese patients as expected, abdominal wound infection was more common in the nonobese group, in other words, the majority of these people who dehisced their abdominal wound did not have an infection. We cannot really explain this. We have theorized that the patient's nutritional status has a lot to do with infection, and you might theorize that a thin cancer patient who is nutritionally more compromised might have a higher infection rate postoperatively than an obese patient who is in a better nutritional state. It's an interesting phenomenon, but we can't explain it any better than that.

MR SCIPIONE: Interesting, all of the wound infections in the nonobese patients occurred in nonobese patients with malignancy as their indication for the transhiatal esophagectomy, so this lends support to the influence of nutrition here. 


\section{Transhiatal Esophagectomy in the Profoundly Obese: Implications and Experience}

Christopher N. Scipione, Andrew C. Chang, Allan Pickens, Christine L. Lau and Mark

$$
\text { B. Orringer }
$$

Ann Thorac Surg 2007;84:376-383

DOI: 10.1016/j.athoracsur.2006.11.070

$\begin{array}{ll}\begin{array}{l}\text { Updated Information } \\ \text { \& Services }\end{array} & \begin{array}{l}\text { including high-resolution figures, can be found at: } \\ \text { http://ats.ctsnetjournals.org/cgi/content/full/84/2/376 } \\ \text { References }\end{array} \\ \text { This article cites } 20 \text { articles, } 10 \text { of which you can access for free at: } \\ \text { http://ats.ctsnetjournals.org/cgi/content/full/84/2/376\#BIBL } \\ \text { Subspecialty Collections } & \begin{array}{l}\text { This article, along with others on similar topics, appears in the } \\ \text { following collection(s): } \\ \text { Esophagus - cancer } \\ \text { http://ats.ctsnetjournals.org/cgi/collection/esophagus_cancer }\end{array} \\ & \begin{array}{l}\text { Requests about reproducing this article in parts (figures, tables) or } \\ \text { in its entirety should be submitted to: } \\ \text { http://www.us.elsevierhealth.com/Licensing/permissions.jsp or } \\ \text { email: healthpermissions@ elsevier.com. }\end{array} \\ \text { Permissions \& Licensing } & \begin{array}{l}\text { For information about ordering reprints, please email: } \\ \text { reprints@ @elsevier.com }\end{array}\end{array}$

